Case Report

\title{
Diagnostic Difficulties in Pathological Laboratories in Developing Countries: A Case Report of Differentiated Squamous Cell Carcinoma in a Young Togolese Woman
}

\author{
Tchin Darré, ${ }^{1}$ Lantam Sonhaye, ${ }^{2}$ Mazamaesso Tchaou, ${ }^{2}$ Abdoul-Samadou Aboubakari, \\ Bingo K. M'Bortche, ${ }^{3}$ Kofi Amégbor, ${ }^{1}$ and Gado Napo-Koura ${ }^{1}$
}

${ }^{1}$ Department of Pathology, The University Teaching Hospital of Lomé, Togo

${ }^{2}$ Department of Imaging, The University Teaching Hospital of Lomé, Togo

${ }^{3}$ Department of Obstetrics and Gynecology, The University Teaching Hospital of Lomé, Togo

Correspondence should be addressed to Tchin Darré; paolodarre@yahoo.fr

Received 14 December 2015; Accepted 23 February 2016

Academic Editor: Showket Hussain

Copyright @ 2016 Tchin Darré et al. This is an open access article distributed under the Creative Commons Attribution License, which permits unrestricted use, distribution, and reproduction in any medium, provided the original work is properly cited.

We report a case of poorly differentiated squamous cell carcinoma of the vulva induced by human papillomavirus in a 23-year-old woman, in whom we experienced diagnostic difficulties.

\section{Introduction}

Vulva cancers are very rare and serious tumors [1]. Infection with human papillomavirus (HPV) is the main risk factor in the occurrence of vulva cancers, especially in young women [2]. We report a case of poorly differentiated squamous cell carcinoma of the vulva in a 23-year-old young woman due to HPV, genotypes $16 / 18$ and $6 / 11$, detected by immunohistochemistry and in situ hybridization. We encountered difficulties in the process of diagnosing this differentiated squamous cell carcinoma of the vulva.

\section{Case Report}

In January 2014, a 23-year-old unmarried woman consulted gynecology department of the "Sylvanus Olympio Teaching Hospital in Lomé" for a painful swelling of the major labia of the vulva. She had her first menstruations at 16 years of age and her first sexual intercourse at 20 years of age. She did not report any history of sexually transmitted infections. She did not smoke, nor take alcohol, nor take contraceptive pill.

Clinical examination revealed axillary temperature of $37^{\circ} \mathrm{C}$, body weight of $75 \mathrm{Kg}$, and height of $1.65 \mathrm{~m}$. Gynecological examination noted, at the major labia of the vulva, a firm swelling of about $2 \mathrm{~cm}$, with regular contours. The major labium of the vulva was painful at contact. There were no satellite adenopathies.

Clinicians established an initial diagnosis of inflammation of Bartholin gland. A tumorectomy was done in February 2014 and the removed piece was sent for histological analysis. Conventional histological analysis of a biopsy performed in February 2014 concluded to a botryoid sarcoma of the vulva. Also, paraffin blocks were sent to France for specific examinations.

Immunohistochemistry investigations showed positivity of anti-epithelial membrane antigen (EMA) markers and anti-pancytokeratin 1 markers of tumor cells, but they were negative for anti-smooth muscle actin and desmin protein S100 ones (Figures 1, 2, and 3).

In situ hybridization revealed the HPV $16 / 18$ and 6/11 genotypes. The diagnosis of squamous cell carcinoma with poorly differentiated sequences of HPV was established. Chemotherapy was instituted.

One year after the beginning of chemotherapy, the patient complained of abdominal and bone pain. Thoracolumbar spine scan showed a metastatic osteolysis of vertebral spondyle and spinous process of the twelfth thoracic vertebra 


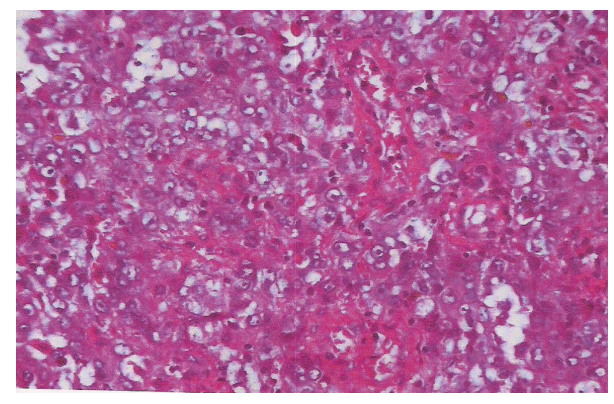

FIGURE 1: Poorly differentiated squamous cell carcinoma of the vulva (HE, $\times 250)$.

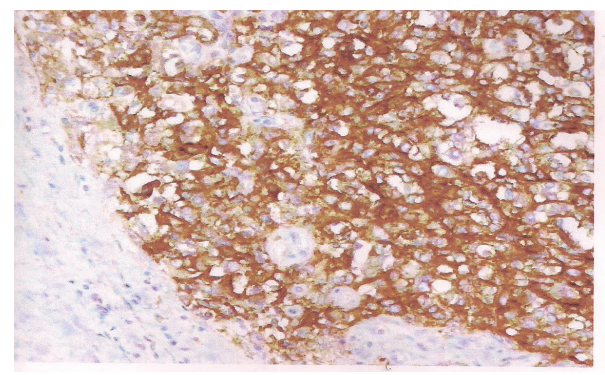

FIGURE 2: Diffuse positivity for anti-EMA tumor cells in immunohistochemistry.

(Figure 4). Abdominal ultrasound had shown no abnormalities. After multidisciplinary discussions, radiotherapy was decided in addition to the chemotherapy.

\section{Comments}

Our reported case illustrates the diagnostic difficulties encountered in practice by the pathological laboratories in sub-Saharan Africa (absence of immunodetection techniques, lack of electron microscopy, and in situ hybridization). In fact, in our case, without the collaboration with a pathological laboratory in France, this diagnosis of squamous cell carcinoma would not have been established. Many studies have confirmed the role of oncogenic HPV in the genesis of neoplasia, as with squamous privileged location [1, 3]. Infections with HPV 16 and 18 are associated with a major risk of genital cancers, causing an increase in the frequency of these cancers [4].

Our clinical cases of squamous cell carcinoma cancer concerned a young woman who showed no particular medical history and who developed a cancer 3 years after her first sexual intercourse. However, the vulvae cancer is observed in the elderly between 6 th and 7 th decade with mucosa estrogen deficiency, according to the literature $[1,3]$. In a study, Zekan et al. found $28 \%$ of HPV in the age group of 20-22 years and the induction period of cancer was estimated between 20 and 30 years after the first sexual intercourse [5]. According to Kokka et al., a woman who had her first sexual intercourse before the age of 16 years has a risk of an oncogenic HPV infection twice higher than the one whose first intercourse occurred after the age of 20 years [6]. The patient in our study

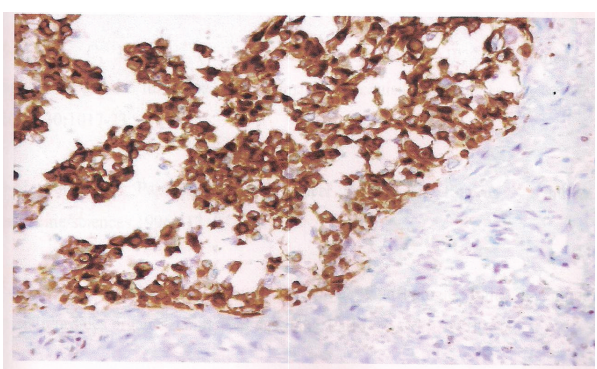

FIGURE 3: Focal positivity for KL1 type of anti-cytokeratin tumor cells in immunohistochemistry, anti-cytokeratin.

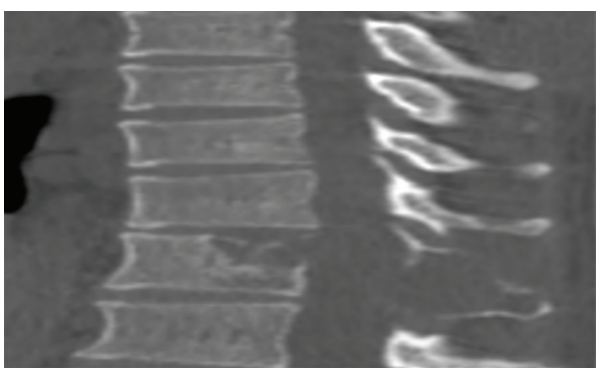

FIGURE 4: Metastatic vertebral osteolysis spondyle and the spinous process of the twelfth thoracic vertebra.

reported to have had her first sexual intercourse at 20 years old and as such was deemed to have a lower risk of developing carcinoma. The risk of developing genital cancer is three times higher in women with almost ten sexual partners than in those having one partner [3]. In our case, the woman had only one sexual partner since her first sexual intercourse.

HPV infection and genital cancers are now considered as opportunistic infections in patients with human immunodeficiency virus [5]. Histologically, cancer of the vulva is a squamous cell cancer in $90 \%$ of cases and sarcomas or melanocarcinomas in $8 \%$ and other histological types are met in $2 \%$ [1]. It is known that immunohistochemical analyses have several advantages in the diagnosis: the positivity of cytokeratin markers and of the epithelial membrane antigen reflects the epithelial nature of this cancer, and the negativity of desmin and smooth muscle actin protein S100 markers allows excluding the diagnosis of sarcoma botrytis. In situ hybridization has allowed isolating the types of HPV. Usually, it is the low potential oncogenic papillomavirus types 6, 11,42 , and 55 which are found in the anogenital region [6]. The poorly differentiated carcinoma due to HPV is consistent with the opinion of $\mathrm{Xu}$ et al. and others who think that the papillomavirus is the instrument of pathology of undifferentiated vulva lesions [7].

On therapeutic side, treatment of this cancer is primarily surgical. Our patient received only chemotherapy with disappointing outcomes. Radiotherapy was required in our patient because chemotherapy combined with radiation therapy is often recommended for extended forms [4]. 


\section{Conclusion}

This case report shows the diagnostic difficulties of infections related to papillomavirus encountered by pathology laboratories in developing countries and poses the problem of providing adequate therapeutic care of such cancers in our country.

\section{Competing Interests}

The authors declare that they have no competing interests.

\section{Authors' Contributions}

Tchin Darré and Kofi Amégbor were responsible for the conception of the study, participated in the study design, performed the laboratory analysis and interpretation, and wrote the paper. Lantam Sonhaye, Mazamaesso Tchaou, Abdoul-Samadou Aboubakari, and Bingo K. M'Bortche were involved in the clinical and therapeutic management of the patient; they have reviewed the paper. Gado Napo-Koura was responsible for the overall scientific management of the study and the preparation of the final paper. All the authors have read and approved the final paper to be submitted for publication.

\section{Acknowledgments}

The authors would like to thank Dr. Dadja Essoya Landoh, epidemiologist, scientific writer, for reviewing and copyediting the paper.

\section{References}

[1] D. Riethmuller, "Ano-genital papillomavirus infections in women," Revue du Praticien, vol. 56, no. 17, pp. 1893-1900, 2006.

[2] E. L. Barlow, Y. Kang, N. F. Hacker, and K. Canfell, "Changing trends in vulvar cancer incidence and mortality rates in Australia since 1982," International Journal of Gynecological Cancer, vol. 25, no. 9, pp. 1683-1689, 2015.

[3] J. Ngamkham, P. Homcha-aim, K. Boonmark, T. Phansri, and S. S. Swangvaree, "Preliminary study on human papillomavirus frequency and specific type-distribution in vulva cancer from thai women," Asian Pacific Journal of Cancer Prevention, vol. 14, no. 4, pp. 2355-2359, 2013.

[4] M. C. Reyes and K. Cooper, "An update on vulvar intraepithelial neoplasia: terminology and a practical approach to diagnosis," Journal of Clinical Pathology, vol. 67, no. 4, pp. 290-294, 2014.

[5] J. Zekan, M. Skerlev, L. Milić, and D. Karelović, "Human papillomavirus-related diseases of the female lower genital tract: oncogenic aspects and molecular interaction," Collegium Antropologicum, vol. 38, no. 2, pp. 779-786, 2014.

[6] F. Kokka, N. Singh, A. Faruqi, K. Gibbon, and A. N. Rosenthal, "Is differentiated vulval intraepithelial neoplasia the precursor lesion of human papillomavirus-negative vulval squamous cell carcinoma?" International Journal of Gynecological Cancer, vol. 21, no. 7, pp. 1297-1305, 2011.

[7] L.-Q. Xu, R.-Z. Luo, X.-M. Sun, J.-H. He, and Y.-N. Zhang, "Prognostic analysis of early-stage squamous cell carcinoma of the vulva," World Journal of Surgical Oncology, vol. 11, article 20, 2013. 


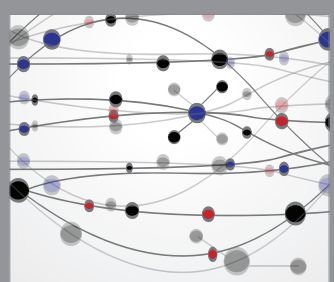

The Scientific World Journal
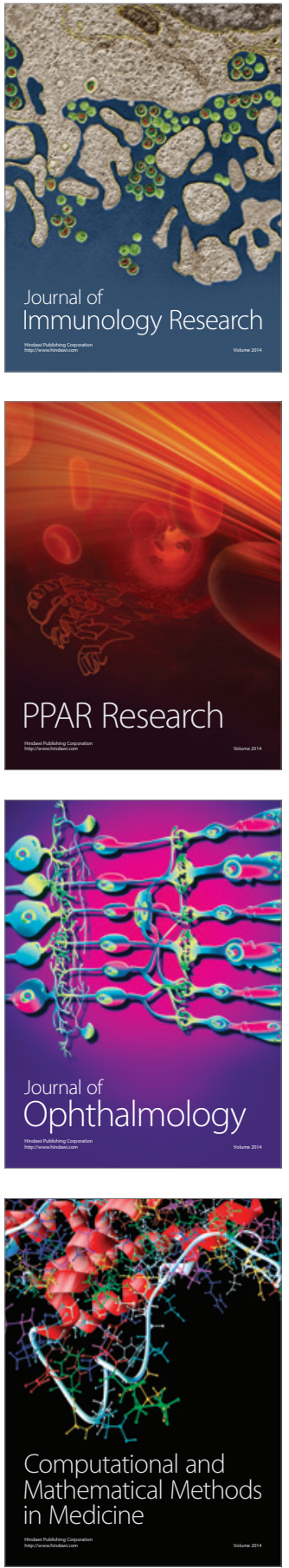

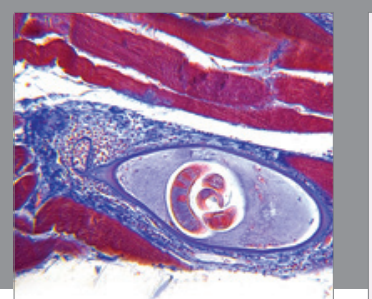

Gastroenterology Research and Practice

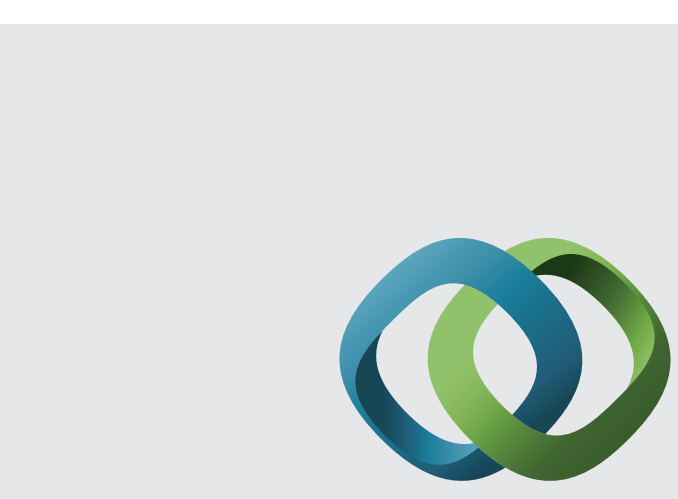

\section{Hindawi}

Submit your manuscripts at

http://www.hindawi.com
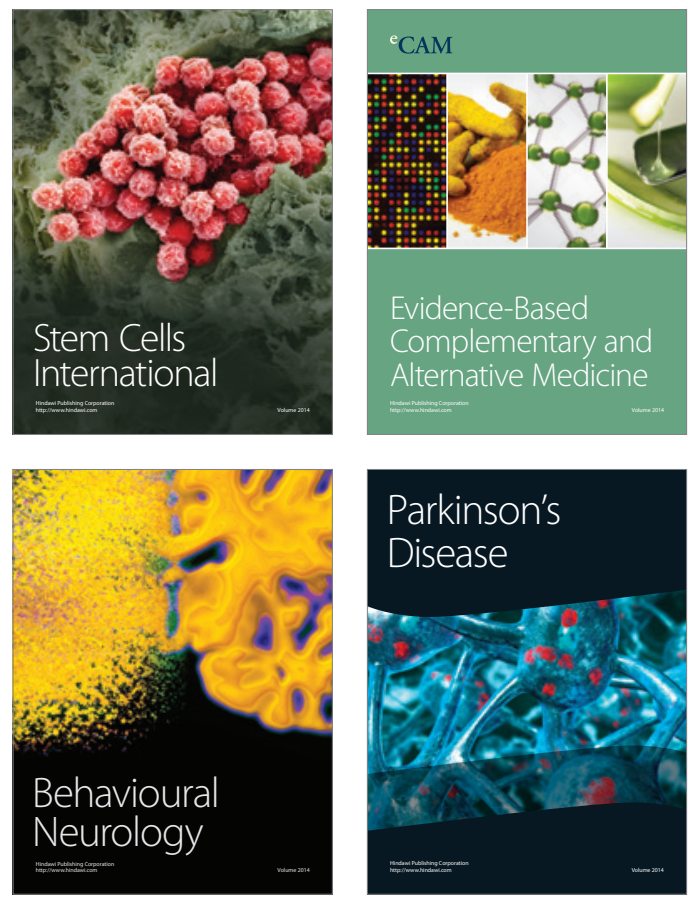
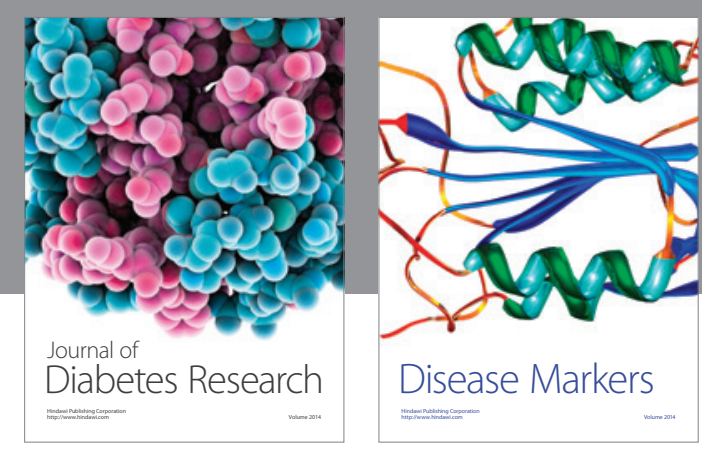

Disease Markers
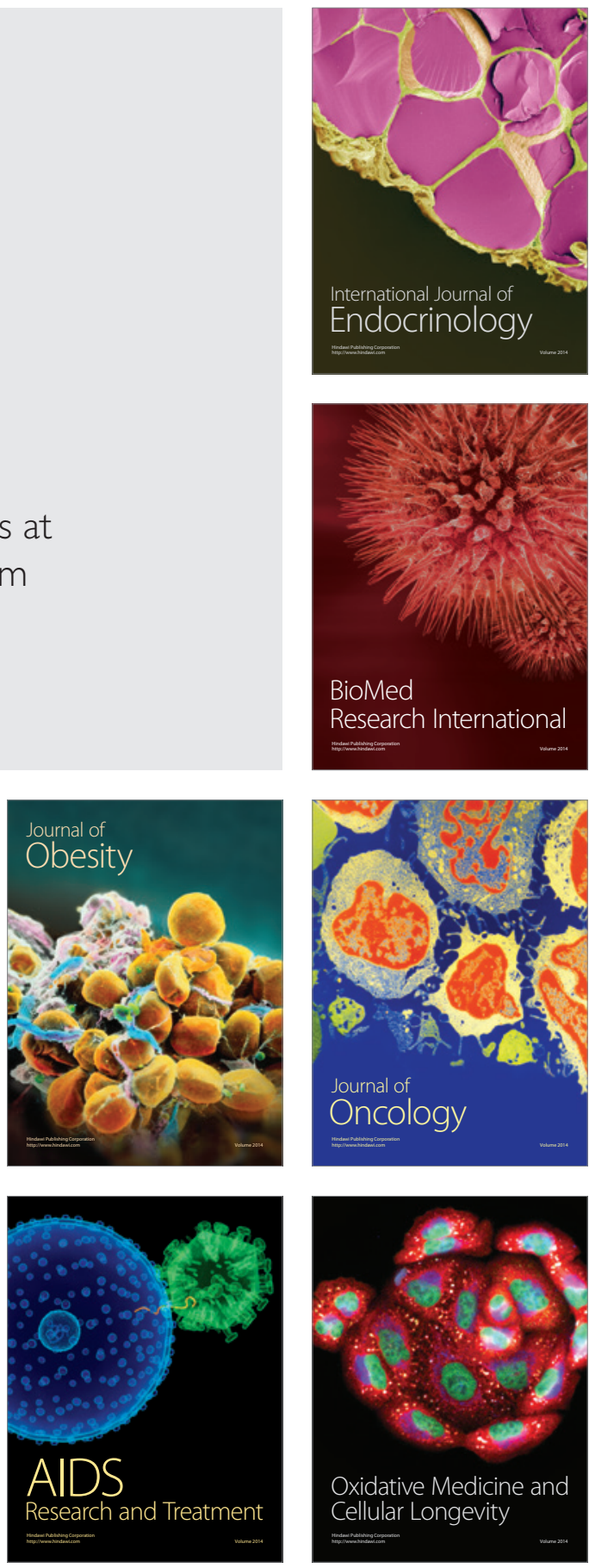